\title{
Evidence for global health
}

\section{Prabhat Jha, James V. Lavery}

ß S See related article page 1673 evels of health in the poorest countries, and in particular among the poor in these countries, remain unacceptably low. ${ }^{1}$ Worldwide, over 10 million children die each year before their fifth birthday. ${ }^{2}$ However, health has improved: if worldwide child mortality rates were equivalent to Canada's rates in 1900, there would be 30 million child deaths annually. Conversely, if Canada's current child mortality rates were found worldwide, only 1 million children would die each year. Progress has been steady in reducing child and maternal mortality, but the world is now in the midst of large and growing epidemics from HIV-1 and tobacco.

Health has improved in developing countries more rapidly over the last half century than it did in Western countries from the 17th century onward. The chief reason has been advances in technology and not - as many believe - improvements in income or education. ${ }^{3}$ Technological advances take many forms: vaccines against childhood and other diseases, better information about the hazards of smoking and the benefits of cessation, diagnostic tests for HIV-1 and short-course therapy for tuberculosis are examples. None would have been possible without high-quality scientific research. Yet despite the promise of knowledge to reduce premature mortality and poverty, only $10 \%$ of the world's health research resources go toward $90 \%$ of the diseases that burden the poorest countries. ${ }^{4}$

Rochon and colleagues ${ }^{5}$ in this issue (see page 1673) describe the paucity of randomized controlled trials (RCTs) addressing major global diseases. They reviewed 286 RCTs published in 6 international peer-reviewed general medical journals to determine which evaluated conditions or diseases listed among the World Health Organization's leading causes of disease burden worldwide in terms of both mortality and disability-adjusted life years (DALYs). Less than half $(43 \%)$ of the trials addressed any of the 35 leading contributors to global disease burden, with vascular disease and HIV/AIDS being the most studied conditions. As well, 12 global health experts rated the relevance of the RCTs that focused on any of the top 10 causes of global burden of disease. The panel returned low ratings overall, judging only 1 in 6 of the selected RCTs to be highly relevant to global health.

Rochon and colleagues' findings help document the lack of evidence from RCTs being directed to global diseases. Comparable findings about research funding and products not matching disease burden have been documented for the US National Institutes of Health (e.g., proportionally, breast cancer research received much more funding than the disease's contribution to US burden of disease). ${ }^{6} \mathrm{Nev}$ ertheless, Rochon and colleagues' analyses, though carefully done, do not present a complete picture. First, RCTs represent only part of what is needed in global health research. For example, the efficacy of some interventions, such as vaccination against childhood diseases (especially measles) and vaccination against hepatitis B for chronic liver cirrhosis and liver cancer, has been established by past RCTs. We know that some vaccines work, but we know less about how to deliver effective vaccines to populations where vaccine coverage is low. Operational research might be better than RCTs to address such gaps in global evidence. $^{4}$

Second, experts bring their own biases to bear when judging the "relevance" of evidence from RCTs. Many who work in global health perceive interventions for maternal and childhood conditions as being more relevant than those for chronic diseases of adults, ${ }^{7}$ but this logic is often misguided. For example, there are 13 million deaths from vascular disease in developing countries as compared with 3 million in developed countries, ${ }^{8}$ and such deaths in developing countries are often concentrated among younger people and the poor. The experts in the study by Rochon and colleagues, even though they used a welldesigned and standardized method to give their ratings, gave the lone randomized trial of road-traffic accidents the lowest relevance rating, despite the top-10 status of roadtraffic accidents in both DALYs and mortality. There is, of course, no easy way to judge priorities. Quantitative burden estimates help, but expert ratings are more problematic.

Finally, although publishing RCTs in high-profile general medical journals undoubtedly has some bearing on the impact of the research, by focusing solely on general medical journals Rochon and colleagues may underestimate the extent of specialization in global health research and therefore the amount of relevant and high-impact research that might be published through specialty journals.

Nonetheless, the analyses by Rochon and colleagues help to point out that not enough research, including RCTs, is being done into the diseases in developing countries. There is renewed interest in Western countries in making a serious dent over the next 2 decades in the major diseases of the global poor. However, in this era of globalization and "outsourcing," the lack of randomized 
studies in developing countries is notable. Barriers include complex ethical challenges, such as those revealed by the randomized HIV-1 perinatal transmission trials in developing countries in the early 1990s, ${ }^{9}$ skepticism of Western regulatory agencies of drugs and devices tested outside of high-income countries and limited research capacity in developing countries. But these barriers are not insurmountable. Making any serious improvement in mortality and disability among the global poor will require much more research, some of it employing randomized designs, into the few major diseases that explain much of the gap between rich and poor countries. Priorities include accelerating declines in childhood and maternal mortality, getting adult smokers worldwide to quit ${ }^{1}$ and, most notably, curbing the growth of HIV $-1 .{ }^{10}$

This article has been peer reviewed.

From the Centre for Global Health Research (Jha, Lavery) and the Centre for Inner City Health Research (Lavery), St. Michael's Hospital, University of Toronto, and the Department of Public Health Sciences (Jha, Lavery) and the Joint Centre for Bioethics (Lavery), University of Toronto, Toronto, Ont.

Competing interests: None declared.

Contributors: Both authors drafted and revised the article and approved the final version.

\section{References}

1. Jha P, Mills A, Hanson K, Kumaranayake L, Conteh L, Kurowski C, et al. Improving the health of the global poor. Science 2002;295:2036-9.

2. Black RE, Morris SS, Bryce J. Where and why are 10 million children dying every year? Lancet 2003;361(9376):2226-34

3. Easterlin RA. How beneficent is the market? A look at the modern history of mortality. Eur Rev Econ Hist 1999;3(3):257-94.

4. World Health Organization. Investing in bealth research and development: report of the Ad Hoc Committee on Health Research Relating to Future Intervention Options. Geneva: The Organization; 1996. Rep no TDR/Gen/96.1.

5. Rochon PA, Mashari A, Cohen A, Misra A, Laxer D, Streiner DL, et al. Relation between randomized controlled trials published in leading general medical journals and the global burden of disease. CMA7 2004;170(11):1673-7.

6. Committe on the NIH Research Priority-Setting Process, Institute of Medicine. Scientific opportunities and public needs: improving priority setting and public input at the National Institutes of Health. Washington: The Institute; 1998

7. Gwatkin DR, Heuveline P. Improving the health of the world's poor. BMf 1997;315(7107):497-8.

8. World Health Organization. World bealth report 2002: making a difference Geneva: The Organization; 2002

9. London AJ. Equipoise and international human subjects research. Bioethics $Q$ 2001;15(4):312-32

10. Jha P, Nagelkerke JD, Ngugi EN, Prasada Rao JV, Willbond B, Moses S, et al. Reducing HIV transmission in developing countries. Science 2001;292 (5515):224-5.

Correspondence to: Dr. Prabhat Jha, Director, Centre for Global Health Research, St. Michael's Hospital, University of Toronto, 70 Richmond St. E, Third floor, Toronto ON M5C 1N8; fax 416 864-5256; prabhat.jha@utoronto.ca

\section{Health care as a risk factor}

\section{Peter Davis}

ß See related article page 1678

$\mathrm{T}$ he article by Baker and associates in this issue (see page 1678) adds to the growing body of evidence that health care, though undoubtedly beneficial, also has potentially harmful effects on patients. ${ }^{1}$ According to the estimates published here, nearly 70000 annual hospital admissions in Canada are associated with an adverse event (AE) that was preventable. Most are relatively minor, but a good proportion (20.8\%) result in death. The impact on an already overtaxed system is not to be underestimated: patients experiencing AEs require a longer stay in hospital and may need more intensive care. What are we to make of these results? Are they sound? If so, what can be done about them? Or, are they a risk that we must accept in a world of increasingly complex and powerful therapeutic interventions with patients who are ever more frail?

Baker and associates followed a swath of investigations with similar methodologies published in the United States, Australia, the United Kingdom, Denmark and New Zealand. ${ }^{2-10}$ This is one of the study's strengths. Science establishes fact by replicating results under different conditions. Indeed, in some respects, this investigation pushes the boundaries in the field. It is probably the first study of AEs that can safely claim to be nationally representative, since the investigators selected hospitals of different sizes from 5 of Canada's most populous provinces. Furthermore, electronic data collection instruments may well have improved accuracy.

In scientific terms, the study results are reassuringly robust and familiar. There are some variations, of course. The overall $\mathrm{AE}$ rate ( $7.5 \%$ of all hospital admissions) is closer to European than to American findings. The proportion of AEs associated with death seems high when compared with that of other studies, and the proportion of AEs attributable to system-related events (just over $3.0 \%$ ) is lower. But in other respects, including the distinctive distribution of AEs across hospital services (higher in surgery) and patient ages (higher among elderly patients), as well as a variety of other factors, the results are comparable with those of other studies.

One conclusion we can draw from this study is that, although the populations of Western societies might enjoy all the benefits of affluence and modern medical care, they 